\title{
AXONAL RAMIFICATIONS OF HIPPOCAMPAL CA1 PYRAMIDAL CELLS $^{1}$
}

\author{
W. DOUGLAS KNOWLES ${ }^{*, 2}$ AND PHILIP A. SCHWARTZKROIN ${ }^{*}+$
}

Departments of *Neurological Surgery and $\ddagger$ Physiology and Biophysics, University of Washington, Seattle, Washington 98195

\begin{abstract}
Intracellular injections of Lucifer Yellow into CA1 pyramidal cells of the in vitro guinea pig hippocampal slice enabled us to examine in detail the morphology of the axons of these neurons. We also recorded the electrophysiological responses of these neurons to alvear stimulation. In our morphological examinations, we found that many axons bifurcate in the alveus, with the major branch projecting caudally toward the subiculum and the second, thinner branch projecting rostrally toward the fimbria. Either axon may bifurcate further to produce several axon branches which follow parallel paths in the alveus. These axons also have local collaterals which project into strata oriens and pyramidale. In addition, a very fine plexus of axonal processes was observed in stratum oriens located largely within the basal dendritic field of the parent cell. Our electrophysiological experiments demonstrated that neurons could be activated antidromically by stimulation of the alveus at sites both rostral and caudal to the neuron. Weak alvear stimulation occasionally evoked small potentials which appeared similar to fast prepotentials. The local axonal ramifications may be involved in recurrent pathways mediating feedback inhibition and/or excitation. The axonal bifurcations also may provide a basis for understanding the origins of fast prepotentials elicited with antidromic stimulation.
\end{abstract}

Until recently, there has been some confusion in the literature regarding the efferent path taken by the axons of the pyramidal cells of the CAl region of the hippocampus. One outstanding question has been whether the CA1 pyramidal cell axons project caudally toward the subiculum, rostrally toward the fimbria/fornix, or both. Lorente de Nó (1934) and Ramón y Cajal (1911) described the axons of CA1 pyramidal cells as seen in Golgi preparations. They claimed that the majority of $\mathrm{CA} 1$ axons project rostrally via the alveus to the fimbria/fornix and have collaterals which project caudally to the subiculum. Some recent anatomical reports have claimed either that the CA1 pyramidal cell axons project caudally to the subiculum (Berger et al., 1980; Hjorth-Simonsen, 1973; Swanson et al., 1978) or that the axons project rostrally to the fimbria/fornix (Chronister and DeFrance, 1979; Gottlieb and Cowan, 1973; Meibach and Siegel, 1977; Raisman et al., 1966; Swanson and Cowan, 1977). A few anatomical reports (Finch and Babb, 1981; Raisman et al., 1965; Rosene and Van Hoesen, 1977; Swanson et al.,

\footnotetext{
'This work was supported by National Institutes of Health Grants NS 04053 and NS 00413 and National Science Foundalion Grant BNS 7915115. We thank W. W. Stewart for supplying the Lucifer Yellow. The Leitz Ploemopak epifluorescence equipment was loaned by Boyle Instruments, Gig Harbor, WA, to whom we are grateful. Dr. Schwartzkroin is an affiliate of the Child Development and Mental Retardation Center, University of Washington.

${ }^{2}$ To whom correspondence should be addressed.
}

1981) have described both caudal and rostral projections. The electrophysiological literature has reported consistently only caudal projections toward the subiculum from CA1 pyramidal cells (Andersen et al., 1971, 1973; Finch and Babb, 1980; Leung, 1979). Taken as a whole, the literature indicates both caudal and rostral CA1 projections, but it has been unclear whether the same cell sends axons in both directions. The most recent reports indicate that the axons of a single pyramidal cell do project both caudally and rostrally (Finch and Babb, 1981; Swanson et al., 1981).

The existence of local CA1 pyramidal cell axon collaterals projecting to neighboring CA1 neurons has been suggested by physiological studies (Alger and Teyler, 1977; Andersen et al., 1973). The local collaterals are thought to mediate recurrent inhibition (Andersen et al., 1964) or excitation (Andersen et al., 1973). These collaterals were demonstrated by Lorente de Nó (1934) and Ramón y Cajal (1911) in Golgi preparations and now have been shown with the injection of single neurons with horseradish peroxidase (Finch and Babb, 1981).

The present study was undertaken to investigate in detail the morphology of the axons of the CA1 pyramidal cells in order to clarify the efferent projections of these neurons. Intracellular injections of the fluorescent dye Lucifer Yellow $\mathrm{CH}$ allowed us to examine these axons in great detail. We found that CA1 pyramidal cell axons bifurcate and send axon branches both rostrally and caudally, that there are local axon collaterals to neigh- 
boring regions of $\mathrm{CA1}$, and that most axons give off fine local axonal plexuses. In short, CA1 axon morphology is more complex than some authors have indicated.

\section{Materials and Methods}

The in vitro guinea pig hippocampal slice preparation was used, and intracellular penetrations and Lucifer Yellow injections were made into CA1 pyramidal cells. This preparation has been described previously (Schwartzkroin, 1975). The electrodes used for dye injection were pulled from thin wall capillary tubing with intraluminal glass fibers (Frederick Haer Co., catalog No. 30-30-0). The electrodes were filled with a $3 \%$ solution of the lithium salt of Lucifer Yellow $\mathrm{CH}$ and had resistances of 100 to 250 megohms. Bipolar stimulating electrodes made from etched tungsten wires were used to stimulate $(0.02$ to $0.5 \mathrm{~mA} \times 50 \mu \mathrm{sec})$ the alveus in order to activate the neurons antidromically. Upon obtaining a "healthy" intracellular penetration (Schwartzkroin, 1977), DC hyperpolarizing current $(0.5$ to $1.0 \mathrm{nA} \times 5$ to $10 \mathrm{~min})$ was passed through the electrode to eject the Lucifer Yellow. After the termination of dye ejection, the slices were allowed to remain in the incubation chamber for at least $1 \mathrm{hr}$. The slices then were removed from the chamber and fixed overnight at $5^{\circ} \mathrm{C}$ in $4 \%$ phosphate-buffered formalin ( $p: 1$ 7.3) between pieces of filter paper to keep the tissue flat. On the following day, the slices were transferred to $30 \%$ sucrose in $0.13 \mathrm{M}$ phosphate buffer (pH 7.3) for $4 \mathrm{hr}$ and then $75-\mu \mathrm{m}$-thick frozen sections were cut. The sections were sealed under a coverslip in $0.13 \mathrm{~m}$ phosphate buffer ( $\mathrm{pH}$ 7.3) on microscope slides and examined with a Leitz Dialux microscope equipped with a Leitz Ploemopak 2.4 epifluorescence attachment with Leitz filter system H2. Photographs were taken using Ektachrome 400 film. In order to make accurate drawings of the paths taken by the axons, various landmarks along the length of the axons and in the surrounding tissue were centered in the field of view at $\times 400$, and the $X-Y$ stage micrometer readings were noted. These readings were used to plot the landmarks on graph paper. The axon was drawn by connecting the landmarks along its length with visual reference being made to the original cell. 'The soma and dendritic processes were traced by projecting a photographic slide of the cell onto the axon drawing.

\section{Results}

In order to fill the axons of CA1 pyramidal cells successfully, it was necessary to allow the slices to remain in the incubation chamber for at least $1 \mathrm{hr}$ following dye ejection. Under these conditions, axons were visible on most (15) of the successfully filled cells. The axon was readily distinguishable from dendrites by its lack of spines, thin diameter, regularly spaced varicosities, and its trajectory into the alveus. Figure 1 shows drawings of four cells in which the axon was well labeled. Figure 2 shows photomicrographs of the details of the axonal ramifications. In every case where an axon was visible, a

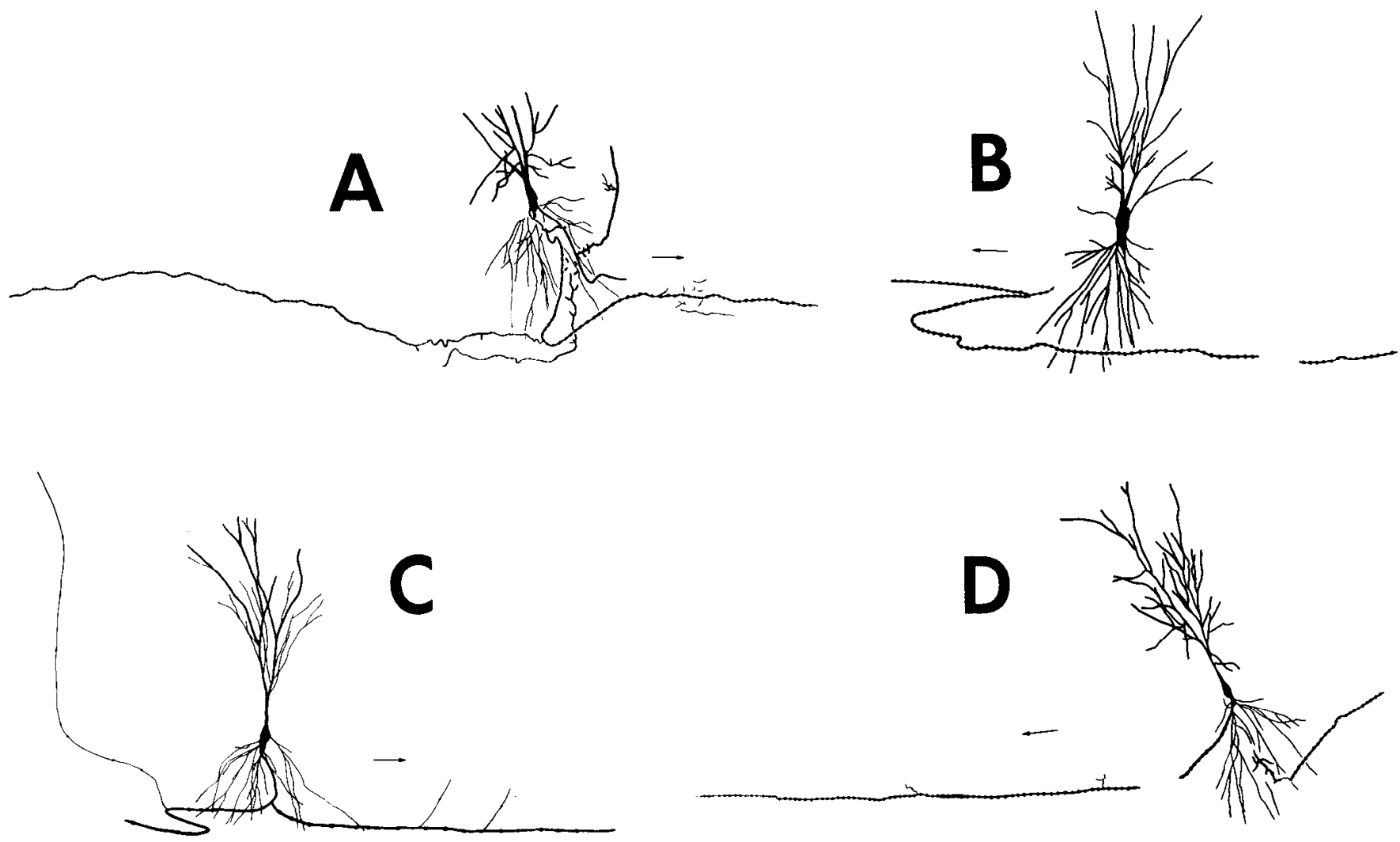

Figure 1. Drawings of four CAl pyramidal cells showing axonal ramifications. The axons have been emphasized in these drawings. In $A, B, C$, and $D$, the axon bifurcates and sends one branch caudally and one branch rostrally. Axon collaterals from the alveus into strata oriens and pyramidale are present in $C$ and $D$. Local axon collaterals within the basilar dendritic field are present in $A$ and $D$. The axon plexus is partially indicated in $A$. The arrows are $100 \mu \mathrm{m}$ in length and point in the caudal direction. 


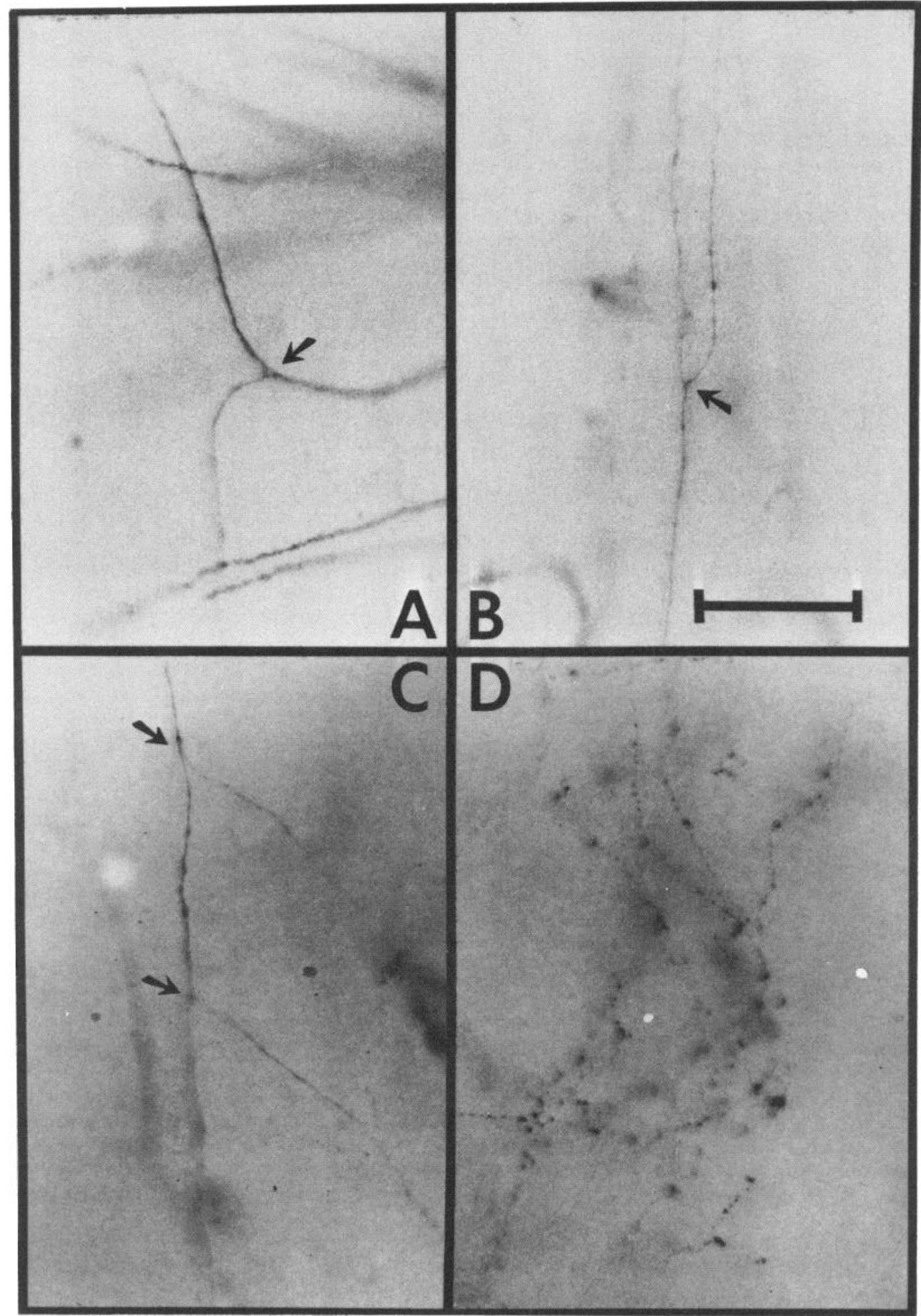

Figure 2. Examples of various types of axonal ramifications. These are negative photographic prints of the Lucifer Yellow-filled cells. $A$, The bifurcation of the axon as it enters the alveus. $B$, The further bifurcation of an axonal branch within the alveus, producing two parallel branches. $C$, Two collaterals branching off of the axon in the alveus and entering stratum oriens. $D$, The axon plexus. The scale bar is $50 \mu \mathrm{m}$ and applies to all four micrographs.

branch could be seen which passed vertically through stratum oriens, entered the alveus, and then projected caudally toward the subiculum. The axon often could be followed as far as $1.5 \mathrm{~mm}$ toward the subiculum in a single $75-\mu \mathrm{m}$-thick section and even further through sev- eral sections of the same slice. One cell was observed to have an axon which projected $2.00 \mathrm{~mm}$ caudally and entered the subiculum. This axon ended in a series of swollen, club-like terminations near the pyramidal cell layer of the subiculum. 


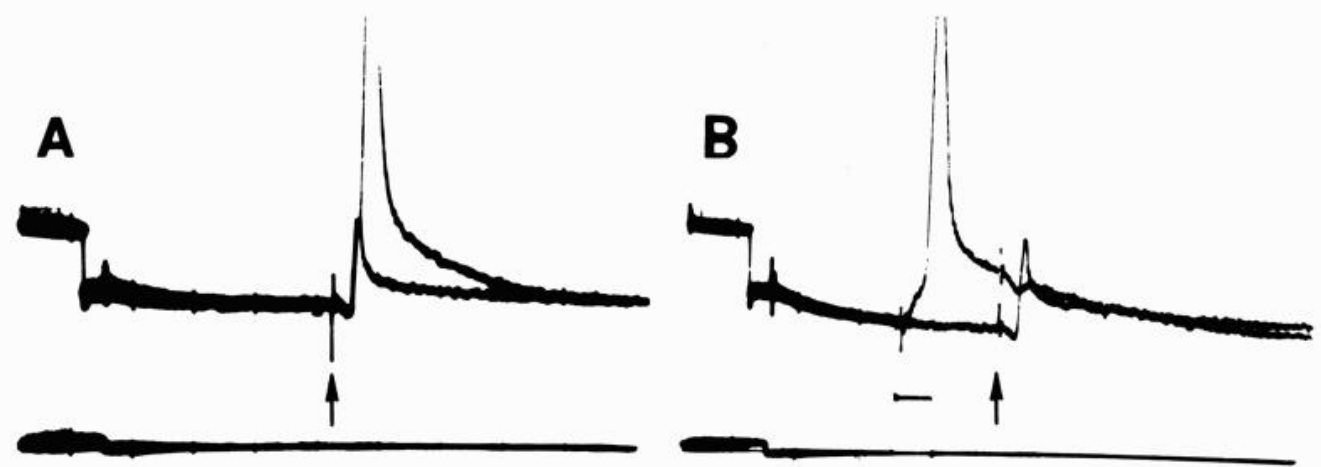

Figure 3. Antidromically activated FPP-like potentials. $A$, Low intensity antidromic stimulation (arrow) produced a small, fast, all-or-none potential, while slightly higher intensity stimulation produced a full action potential. $B$, Antidromic stimulation (arrow) produced a FPP-like depolarization, which was blocked by a preceding orthodromically propagating action potential elicited by an intracellular current pulse. A $10 \mathrm{mV} \times 5 \mathrm{msec}$ calibration pulse is shown at the beginning of each voltage trace. The lower traces monitor the current injected; a $5 \mathrm{nA} \times 3 \mathrm{msec}$ depolarizing pulse is shown in $B$. In each recording, a $0.5-\mathrm{nA}$ current pulse (lower traces) was injected into the cell to slightly hyperpolarize it during stimulations.

In seven of the cells, a second branch of the axon could be seen which projected rostrally toward the fimbria (Fig. 1). This branch originated from a bifurcation of the main axon just before it entered the alveus (Fig. $2 A$ ) and often made a looping turn before assuming its rostral course. The rostral branch was smaller in diameter than the caudally projecting branch but was otherwise similar in appearance and could be seen projecting as far as 1.5 $\mathrm{mm}$ in a single $75-\mu \mathrm{m}$-thick section. In the alveus, both rostral and caudal axon collaterals were occasionally seen to split further into two or more branches which then continued to follow roughly parallel paths through the alveus (Fig. $2 B$ ).

About half of the neurons with filled axons had visible local collateral axon branches. These collaterals could be seen in two locations. Some collaterals originated from the axon along its length in the alveus and extended vertically into stratum oriens (Figs. $1, C$ and $D$ and $2 C$ ). These local collaterals were thinner in diameter than the parent axon branch, had fewer varicosities, and could rarely be traced further than $100 \mu \mathrm{m}$ into stratum oriens. They occasionally appeared to terminate (in strata oriens and pyramidale) in swollen, club-like endings. Other local axon collaterals originated from the vertical portion of the parent axon in stratum oriens (Fig. $1, A$ and $D$ ). These collaterals appeared to be only slightly thinner than the parent axon and had regularly spaced varicosities along their length. They usually branched several times and appeared to be largely confined within the basal dendritic field of the parent cell (but occasionally extended to stratum pyramidale).

A final feature observed in these dye-filled neurons was a very fine plexus of axonal processes which was located in stratum oriens mostly within the basal dendritic field of the parent cell (Fig. 2D). The extremely fine processes within this axonal plexus were just visible at $\times 400$ magnification. The processes appeared smooth with swellings at the junctions or branch points. The exact configuration of the fine plexus was difficult to visualize, but the plexus could be seen to originate from a branch of the parent axon.
Intracellular electrophysiological data were obtained from many of the CA1 pyramidal cells filled with Lucifer Yellow. It was possible to activate CA1 pyramidal cells antidromically by stimuli delivered to sites in the alveus located both caudal and rostral to the recording electrode. Higher intensity currents were required to drive cells antidromically from the rostral side than from the caudal side. Given the probability of some current spread into stratum oriens, it was not always possible to be sure that cell axons, rather than basal dendrites, were being activated. This possibility seemed remote, however, when the stimulating electrode was more than $1 \mathrm{~mm}$ away from the recording site. Occasionally, low amplitude, fast rising depolarizing potentials were elicited at short latencies by low amplitude antidromic stimulation (Fig. $3 A$ ). Such potentials resembled the fast prepotentials (FPPs) previously described in the hippocampus (Spencer and Kandel, 1961; Schwartzkroin, 1977). Increasing the amplitude of the antidromic stimulation resulted in full antidromic spikes (Fig. $3 A$ ). When a brief depolarizing current pulse was injected intracellularly to elicit an action potential preceding the antidromically elicited potential, both the small potentials and full antidromic spikes could be blocked (Fig. $3 B$ ), presumably by collision with the orthodromically traveling spike.

\section{Discussion}

Three main morphological features of CA1 pyramidal cell axons have been described in this report. First, many CA1 pyramidal cell axons bifurcate upon reaching the alveus and send branches both caudally toward the subiculum and rostrally toward the fimbria; these axons sometimes branch further, sending parallel axonal processes along the alveus. Second, local collaterals extend from the axon into stratum oriens; these local collaterals occur both within the basal dendritic field of the parent cell and along the length of the axonal branches in the alveus. Third, axons give off a very fine axonal plexus located mainly within the basal dendritic field of these neurons.

The present demonstration confirms the dual projec- 
tions of some CA1 pyramidal cells. It is apparent that many CA1 pyramidal cells project caudally and rostrally. The exact percentage of neurons with dual projections is difficult to determine because of the variability of the dye injections. However, Swanson et al. (1981), using retrograde transport of two different fluorescent dyes, have demonstrated dual projections in at least $90 \%$ of these neurons. It is likely that previous studies which described only one or the other of these projections were limited, by their methods or experimental design, to finding only one pathway at a time. The small diameter (and thus presumably higher threshold) of the rostrally projecting axons may explain the difficulty of demonstrating this pathway using antidromic stimulation techniques (Andersen et al., 1973; Finch and Babb, 1980; Leung, 1979). In addition, these previous physiological experiments were all done in vitro, where it may be more difficult to align the stimulating and recording electrodes to achieve antidromic activation of the high threshold rostral axons without using inordinately high stimulus amplitudes. Finch and Babb (1980) did report a single CA1 neuron which could be activated antidromically from a rostral site. The different axon branches also may have different transport properties (Anderson and McClure, 1973), which could confound anatomical investigations which rely on orthograde or anterograde transport of labels.

Our finding of apparent axon terminals in the subiculum supports the conclusion that the $\mathrm{CA} 1$ pyramidal cells project to the subiculum (Berger et al., 1980; Rosene and Van Hoesen, 1977; Swanson et al., 1978). We were unable to determine the final projection site of the rostral axons in our experiments. Others have reported that these cells project to the lateral septal nucleus (Chronister and DeFrance, 1979; Meibach and Siegel, 1977; Rosene and Van Hoesen, 1977; Swanson and Cowan, 1977).

The demonstration of local axon collaterals supports suggestions made by Alger and Teyler (1977) and Andersen et al. (1973) that there are local associational connections within the CA1 region. The apparent termination of axon collaterals in strata oriens and pyramidale provides an anatomical substrate for the synaptic connections suggested by these authors. These local collaterals are in the appropriate location to mediate recurrent inhibition via inhibitory interneurons located in strata oriens and pyramidale (Andersen et al., 1964; Knowles and Schwartzkroin, 1981) and also could mediate recurrent excitation either directly (Andersen et al., 1973) or via excitatory interneurons (Andersen et al., 1969).

The functional properties of the fine axonal plexus are unknown. Inasmuch as the plexus appeared to be limited in extent to the immediate vicinity of the parent cell, the possibility that this axonal network makes synapses onto the parent cell (autapses; Peters and Proskauer, 1980; Van der Loos and Glaser, 1972) cannot be ignored. Such processes could be involved in the regenerative bursts of action potentials seen in these cells under epileptogenic conditions (e.g., Prince, 1978; Schwartzkroin and Prince, 1977; Schwartzkroin and Wyler, 1980). Further, it is possible that the local axon plexus and/or the local axon collaterals are involved in the synchronization of neural activity which occurs during epileptogenesis.
The observation of FPP-like activity with antidromic stimulation has been reported previously (Schwartzkroin and Prince, 1980) but is something of a puzzle given the widely held hypothesis that FPPs represent dendritic spikes (Spencer and Kandel, 1961; Schwartzkroin, 1977). The possibility of dendritic activation by alveus stimulation cannot be excluded in our experiments. However, the existence of parallel axon branches in the alveus provides the basis for another explanation for the small, fast, antidromic potentials. Low intensity stimulation of the alveus may activate only one of several parallel branches of the axon. The antidromic spike in that axonal process might fail upon reaching a branch point due to impedance mismatching. Using mathematical models of nonmyelinated axons (Goldstein and Rall, 1974; Parnas and Segev, 1979), one can predict failure of spike propagation at the branch point if the originally activated branch is less than one-third the size of the two other branches (W. H. Calvin, personal communication). If the antidromic spikc did fail at the branch point, the somatic recording electrode would measure only the passively spread portion of the spike. If the stimulus intensity were increased, more of the parallel axon branches within the alveus could be activated and the resulting action currents would be large enough for the antidromic spike to pass successfully by the branch point to invade the soma. The recording electrode then would measure a full somatic spike. If the conduction times in various axon branches were not identical, the somatic electrode might record a passively spread, small, fast, antidromic potential immediately preceding, or on the rising phase of, the full action potential. It has been reported that FPPs are seen with increased frequency in epileptogenic preparations (Schwartzkroin and Prince, 1980). If they are, at least in part, a reflection of antidromic activity in the axons, such an increase in FPP frequency would reinforce the importance of antidromic (or "backfiring") activity (Gutnick and Prince, 1972; Schwartzkroin et al., 1975) in epileptogenic tissue.

It is clear that the axonal morphology of CA1 neurons is rather complex. Finch and Babb (1981), using horseradish peroxidase injections, also have demonstrated extensive axonal ramifications. Their morphological results were similar to ours; however, they did not observe apparent synaptic terminations nor the fine axonal plexus. Just as recent research has shown that dendrites may play an active, complicated role in cell function, it appears that axons, too, may carry out complex functions. The further integrated use of morphological staining and electrophysiological techniques may help to elucidate some of these functions.

\section{References}

Alger, B. E., and 'T. J. Teyler (1977) A monosynaptic fiber track studied in vitro: Evidence of a hippocampal CA1 associational system? Brain Res. Bull. 2: 355-365.

Andersen, P., J. C. Eccles, and Y. Løyning (1964) Pathway of postsynaptic inhibition in the hippocampus. J. Neurophysiol. 27: 608-619.

Andersen, P., G. N. Gross, T. Lømo, and O. Sveen (1969) Participation of inhibitory and excitatory interneurones in the control of hippocampal cortical output. In The Interneu- 
ron, M. A. B. Brazier, ed., University of California Press, Berkeley.

Andersen, P., T. V. P. Bliss, and K. K. Skrede (1971) Lamellar organization of hippocampal excitatory pathways. Exp. Brain Res. 13: 222-238.

Andersen, P., B. H. Bland, and J. D. Dudar (1973) Organization of the hippocampal output. Exp. Brain Res. 17: 152-168.

Anderson, L. E., and W. O. McClure (1973) Differential transport of protein in axons: Comparison between the sciatic nerve and dorsal columns of cat. Proc. Natl. Acad. Sci. U. S. A. 70: 1521-1525.

Berger, T. W., G. W. Swanson, T. A. Milner, G. S. Lynch, and R. F. Thompson (1980) Reciprocal anatomical connections between hippocampus and subiculum in the rabbit: Evidence for subicular innervation of regio superior. Brain Res. 183: 265-276.

Chronister, R. B., and J. F. DeFrance (1979) Organization of projection neurons of the hippocampus. Exp. Neurol. 66: 509523.

Finch, D. M., and T. L. Babb (1980) Neurophysiology of the caudally directed hippocampal efferent system in the rat: Projections to the subicular complex. Brain Res. 197: 11-26.

Finch, D. M., and T. L. Babb (1981) Demonstration of caudally directed hippocampal efferents in the rat by intracellular injection of horseradish peroxidase. Brain Res. 214: 405-410.

Goldstein, S. S., and W. Rall (1974) Changes of action potential shape and velocity for changing core conductor geometry. Biophys. J. 14: 731-757.

Gottlieb, D. I., and W. M. Cowan (1973) Autoradiographic studies of the commissural and ipsilateral association connections of the hippocampus and dentate gyrus of the rat. J. Comp. Neurol. 149: 393-422.

Gutnick, M. J., and D. A. Prince (1972) 'Thalamocortical relay neurons: Antidromic invasion of spikes from a cortical epileptogenic focus. Science 176: 424-426.

Hjorth-Simonsen, A. (1973) Some intrinsic connections of the hippocampus in the rat: An experimental analysis. J. Comp. Neurol. 147: 145-162.

Knowles, W. D., and P. A. Schwartzkroin (1981) Local circuit synaptic interactions in hippocampal brain slices. J. Neurosci. 1: 318-322.

Leung, L. S. (1979) Potentials evoked by alvear tract in hippocampal CA1 regions of rats. I. Topographical projection, component analysis, and correlation with unit activities. J. Neurophysiol. 42: 1557-1570.

Lorente de Nó, R. (1934) Studies on the structure of the cerebral cortex. II. Continuation of the study on the ammonic system. J. Psychol. Neurol. (Lpz.) 46: 113-177.

Meibach, R. C., and A. Siegel (1977) Efferent connections of the hippocampal formation in the rat. Brain Res. 124: 197224.

Parnas, I., and I. Segev (1979) A mathematical model for conduction of action potentials along bifurcating axons. J. Physiol. (Lond.) 295: 323-343.
Peters, A., and C. C. Proskauer (1980) Synaptic relationships between a multipolar stellate cell and a pyramidal neuron in the rat visual cortex. A combined Golgi-electron microscope study. J. Neurocytol. 9: 163-183.

Prince, D. A. (1978) Neurophysiology of epilepsy. Annu. Rev. Neurosci. 1: 395-415.

Raisman, G., W. M. Cowan, and T. P. S. Powell (1965) The extrinsic, afferent, commissural and association fibres of the hippocampus. Brain 88: 963-969.

Raisman, G., W. M. Cowan, and T. P. S. Powell (1966) An experimental analysis of the efferent projection of the hippocampus. Brain 8.9: 83-108.

Ramón y Cajal, S. (1911) Histologie du systeme nerveux de l'homme et des vertebres, S. A. Maloine, Paris.

Rosene, D. L., and G. W. Van Hoesen (1977) Hippocampal efferents reach widespread areas of cerebral cortex and amygdala in the rhesus monkey. Science 198: 315-317.

Schwartzkroin, P. A. (1975) Characteristics of CA1 neurons recorded intracellularly in the hippocampal in vitro slice preparation. Brain Res. 85: 423-436.

Schwartzkroin, P. A. (1977) Further characteristics of hippocampal CA1 cells in vitro. Brain Res. 128: 53-68.

Schwartzkroin, P. A., and D. A. Prince (1977) Penicillin-induced epileptiform activity in the hippocampal in vitro preparation. Ann. Neurol. 1: 463-469.

Schwartzkroin, P. A., and D. A. Prince (1980) Changes in excitatory and inhibitory synaptic potentials leading to epileptogenic activity. Brain Res. 183: 61-76.

Schwartzkroin, P. A., and A. R. Wyler (1980) Mechanisms underlying epileptiform burst discharge. Ann. Neurol. 7: 95107.

Schwartzkroin, P. A., R. Mutani, and D. A. Prince (1975) Orthodromic and antidromic effects of a cortical epileptiform focus on ventrolateral nucleus of the cat. J. Neurophysiol. 38: 795-811.

Spencer, W. A., and E. R. Kandel (1961) Electrophysiology of hippocampal neurons. IV. Fast prepotentials. J. Neurophysiol. 21 : $272-285$.

Swanson, L. W., and W. M. Cowan (1977) An autoradiographic study of the organization of the efferent connections of the hippocampal formation in the rat. J. Comp. Neurol. 172: 4984.

Swanson, L. W., J. M. Wyss, and W. M. Cowan (1978) An autoradiographic study of the organization of intrahippocampal association pathways in the rat. J. Comp. Neurol. 181: $681-716$.

Swanson, L. W., P. E. Sawchenko, and W. M. Cowan (1981) Evidence for collateral projection by neurons in Ammon's horn, the dentate gyrus, and the subiculum: A multiple retrograde labeling study in the rat. J. Neurosci. 1: 548-559.

Van der Loos, H., and E. M. Glaser (1972) Autapses in neocortex cerebri: Synapses between a pyramidal cell's axon and its own dendrites. Brain Res. 48: 355-360. 